\title{
A rare case of sudden blindness due to a pituitary adenoma coincidentally infected with methicillin-resistant Staphylococcus aureus (MRSA)
}

\author{
Nicolaas A. Bakker • Eelco W. Hoving
}

Received: 7 September 2009 / Accepted: 19 October 2009/Published online: 14 November 2009

(C) The Author(s) 2009. This article is published with open access at Springerlink.com

Keywords Pituitary $\cdot$ Abscess $\cdot$ Sudden blindness

Dear editor,

A patient with sudden complete loss of vision is presented, which ultimately turned out to be caused by a pituitary adenoma coincidentally infected with MRSA.

A 39-year-old male patient woke up with complete blindness of both eyes. History taking revealed slightly blurred vision for several weeks. Also, the patient suffered from a nose bleeding and nasal discharge for which he visited his general practitioner. No further action was taken at that time. On physical examination, we saw an acutely ill patient (body temperature, $39^{\circ} \mathrm{C}$ ) with complete blindness, but without any focal neurological deficit. Magnetic resonance imaging (MRI) showed a sellar mass with suprasellar expansion and compression of the optic chiasm (Fig. 1a). Also, the right sphenoid sinus was filled with debris, possibly in continuity with the suprasellar region. Laboratory testing did not reveal any endocrine disturbances, while leukocyte and C-reactive protein count were slightly elevated.

An emergency left-sided pterional craniotomy was performed to decompress the optic system. During surgery, to our surprise, extensive signs of infection were seen, with debris and pus in the interhemispheric fissure and around the suprasellar mass. After surgery, the patient was

N. A. Bakker $(\bowtie) \cdot$ E. W. Hoving

Department of Neurosurgery,

University Medical Center Groningen, University of Groningen,

P.O. Box 30.001, 9700 RB Groningen, The Netherlands

e-mail: n.a.bakker@nchir.umcg.nl admitted to the intensive care unit, while upfront therapy with broad spectrum antibiotics (intravenous ceftriaxone, metrodinazole and penicillin) was initiated. Pathologic examination revealed a non-functioning adenoma, while infection with MRSA was determined in the same specimen 1 day after surgery. Subsequently, intravenous Vancomycin was added.

Direct postoperative MRI showed adequate decompression of the optic system. However, the right sphenoid sinus was still filled with debris. Subsequently, the ear, nose and throat physician performed a sphenoidectomy. A mass was evacuated that contained MRSA. Additional history taking revealed that, approximately 6 months before admission, the patient had adopted a child from Brazil who was treated for MRSA.

In the days after surgery, the patients' clinical course declined dramatically with cerebritis, ventriculitis and meningitis, also requiring external ventricular drainage. The patient still suffered from complete blindness. However, after 3 weeks of intensive antibiotic treatment (systemic and intrathecal), the patient showed signs of recovery, after which he was weaned from the ventilator. Two months after surgery, the patient was discharged with a ventriculoperitoneal shunt device. At that time, the patient was able to have light perception. On a visit at our outpatient department 6 months after surgery, the patient's vision was almost completely recovered, and he did not suffer from any focal neurological deficit. MRI showed adequate decompression of the optic system with a small tumour remnant (Fig. 1b). Because of the involvement of the cavernous sinus within the remnant, total surgical resection was considered to be impossible. For that reason, the patient received radiotherapy on the remnant. 
Fig. 1 a Preoperative

T2-weighted coronal MR image showing a sellar mass with suprasellar expansion and severe compression of the chiasm. It has a somewhat dumbbell shape. b Postoperative T1-weighted contrast-enhanced, coronal MR image showing a contrastenhancing sellar mass remnant, while the optic chiasm is adequately decompressed
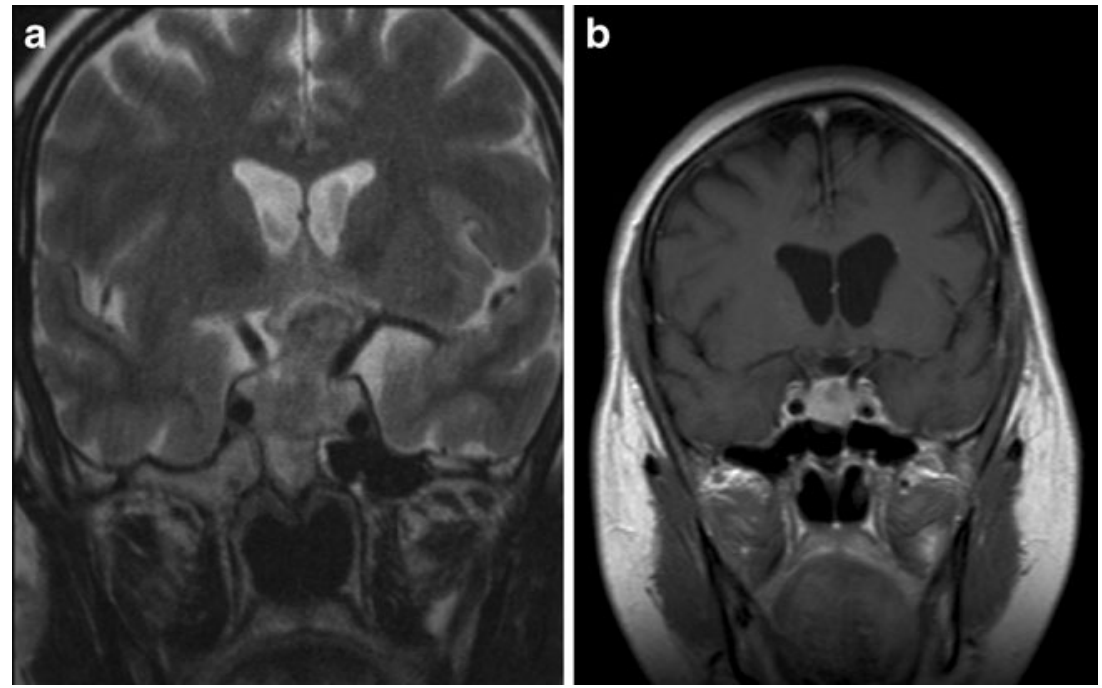

Pituitary abscess itself is rare, with an incidence of less than $1 \%$ of all cases of pituitary disease [2, 3, 7], and radiological distinction from other sellar masses is difficult $[4,5]$. As a result, pituitary abscesses are often diagnosed only during surgery when empyema or pus is found.

Primary pituitary abscess may develop in a normal pituitary gland, either due to haematogenous seeding or by direct extension of adjacent infection (either in the CSF or sphenoid sinus) [2]. Secondary pituitary abscesses occur in glands that harbour a pre-existing lesion, such as an adenoma [3]. Other risk factors are an underlying immunocompromised condition, previous pituitary surgery or irradiation of the pituitary gland.

Our patient probably suffered from a pre-existing pituitary adenoma, secondarily infected by an infection in the sphenoid sinus. This may also explain the clinical course of our patient: a history of blurred vision because of the macro-adenoma, with a co-existing nasal discharge because of the sphenoid sinus infection. The sudden loss of vision may be explained by a sudden rupture of an abscess wall or because of a sudden breakthrough of pus and debris from the sphenoid sinus into the pituitary cavity. Another explanation may be inflammation of the optic nerves due to the infected adenoma [6].

One could discuss the transcranial approach that was performed in this patient, as it is argued that a transsphenoidal approach should be favoured over transcranial surgery as it may limit the spread of micro-organisms $[1,7]$.

However, because of the sudden complete blindness, we wanted to be absolutely sure that the optic chiasm was immediately decompressed in an adequate manner. In addition, as can be seen on the preoperative coronal view (Fig. 1b), the process has a somewhat dumbbell shape, which may limit adequate transsphenoidal decompression. Also, retrospectively, significant cerebral dissemination was already present before the patient was operated on.

Open Access This article is distributed under the terms of the Creative Commons Attribution Noncommercial License which permits any noncommercial use, distribution, and reproduction in any medium, provided the original author(s) and source are credited.

\section{References}

1. Ciappetta P, Calace A, D'Urso PI, De Candia N (2008) Endoscopic treatment of pituitary abscess: two case reports and literature review. Neurosurg Rev 31:237-246

2. Dutta P, Bhansali A, Singh P, Kotwal N, Pathak A, Kumar Y (2006) Pituitary abscess: report of four cases and review of literature. Pituitary 9:267-273

3. Jain KC, Varma A, Mahapatra AK (1997) Pituitary abscess: a series of six cases. Br J Neurosurg 11:139-143

4. Rennert J, Doerfler A (2007) Imaging of sellar and parasellar lesions. Clin Neurol Neurosurg 109:111-124

5. Sabbah P, Bonardel G, Herve R, Marjou F, Hor F, Pharaboz C, Bauduceau B (1999) CT and MRI findings in primitive pituitary abscess: a case report and review of literature. J Neuroradiol 26:196-199

6. Utsuki S, Oka H, Tanaka S, Iwamoto K, Hasegawa H, Hirose R, Fujii K (2005) Blurred vision caused by inflammation of the optic nerves due to a pituitary abscess. Neurol Med Chir (Tokyo) 45:327-330

7. Vates GE, Berger MS, Wilson CB (2001) Diagnosis and management of pituitary abscess: a review of twenty-four cases. J Neurosurg 95:233-241 